\title{
Os "rolês" do movimento negro brasileiro na atualidade, nas "pegadas" da educação
}

\author{
[ The "rolês" of the Brazilian black movement today, in the "footprint" of education
}

\author{
Amilcar Araujo Pereira ${ }^{\mathrm{T}}$ \\ Jorge Lucas Maia ${ }^{2}$ \\ Thayara Cristine Silva de Lima ${ }^{3}$
}

Agradecemos a Cristina Lopes e a Selma Moreira por tornarem possível a realização da pesquisa de campo que resultou neste artigo, através de sua atuação no Baobá - Fundo para Equidade Racial. Agradecemos ainda o apoio do Conselho Nacional de Desenvolvimento Científico e Tecnológico (CNPq) por meio do financiamento obtido através do edital Universal de 2016.

RESUMO-Este artigo é um dos resultados da pesquisa "Movimento negro na atualidade". A partir de metodologia combinada, com a análise de formulários on-line e de entrevistas de história oral, tivemos acesso a $26 \mathrm{I}$ militantes antirracistas de todo o país, dos quais entrevistamos Io\%, em sete estados, distribuídos entre as cinco diferentes regiões do Brasil. O objetivo é apresentar algumas das principais características do movimento negro brasileiro na atualidade e algumas das principais estratégias, frentes de atuação, demandas e referenciais adotados por esse movimento social, no esforço de compreender de que maneira seus militantes têm construído a luta antirracista nos mais diversos campos, especialmente na área da educação. •

PALAVRAS-CHAVE - Movimento negro; antirracismo; educação; Brasil. • ABSTRACT · This article is one of the results of a research conducted based on the analysis of an online forms answered by 26I antiracist militants from all over the country and also on oral history interviews conducted with about Io\% of respondents to the form in seven states, distributed among the five different regions of Brazil. The aim of this article is to present some of the main features of the Brazilian black movement today and some of the main strategies, fronts of action, demands and references adopted by this social movement, in the effort to understand in what ways its militants have been built the antiracist struggle in the most diverse fields, especially in the area of education. - KEYWORDS - Black movement; anti-racism; education; Brazil.

Recebido em 22 de novembro de 2018

Aprovado em 24 de janeiro de 2020

PEREIRA, Amilcar Araujo; MAIA, Jorge Lucas; LIMA, Thayara Cristine Silva de. Os "rolês" do movimento negro brasileiro na atualidade, nas "pegadas" da educação. Revista do Instituto de Estudos Brasileiros, Brasil, n. 75, p. I62-I83, abr. 2020.

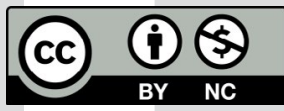

DOI: http://dx.doi.org/Io.II6o6/issn.23I6-90IX.voi75pI62-I83

I Universidade Federal do Rio de Janeiro (UFRJ, Rio de Janeiro, RJ, Brasil).

2 Universidade Federal do Rio de Janeiro (UFRJ, Rio de Janeiro, RJ, Brasil).

3 Universidade Federal do Rio de Janeiro (UFRJ, Rio de Janeiro, RJ, Brasil). 
No final de 2013 a população negra, jovem e periférica esteve em evidência na agenda de debates no Brasil. Usando como ferramenta as redes sociais, jovens da periferia de São Paulo organizaram encontros em shopping-centers da cidade. Esse movimento, surgido do desejo de ocupar espaços de lazer e sociabilidade restritos a grupos sociais específicos, marcadamente brancos e de classe média e classe alta, teve grande repercussão na mídia brasileira. O incômodo gerado a partir da presença desses jovens em espaços "reservados" à elite branca ficou evidente4. As lojas fecharam mais cedo, houve tumultos em corredores, a polícia utilizou bombas de gás lacrimogêneo e balas de borracha para dispersar os participantes que estavam ocupando esse espaço em busca de lazer e, mesmo sem registro de feridos ou de roubos, "suspeitos" foram levados para averiguação em delegacias de polícia. Toda essa ação e a reação mobilizaram, de maneira significativa, debates na sociedade brasileira. Não faltaram coberturas jornalísticas, manchetes, "trending topics" e manifestações nas redes sociais. Popularizava-se, nesse contexto, o fenômeno dos "rolezinhos", mais um capítulo da tensão acerca do acesso da população negra a espaços de poder em nosso país.

Esse tipo de reação à presença da juventude negra e periférica em determinados espaços não é, no entanto, uma novidade. Episódios de manifestação de estranhamento e mesmo repulsa à presença do corpo negro em espaços de poder, historicamente brancos e "de elite", têm feito parte da rotina na sociedade brasileira há muito tempo. Numa escala maior de impacto na sociedade, a partir do ano de 200I, o debate sobre a reserva de vagas (cotas) para estudantes negros nas universidades públicas no Brasil "pegou fogo". Segundo o militante negro e reconhecido advogado constitucionalista Hédio Silva Jr., "possivelmente na República não houve um tema que tenha mobilizado tanta energia quanto a questão das cotas, a favor e contra" (apud ALBERTI; PEREIRA, 2007, p. 397). Esse tipo de política de ação afirmativa, defendida pelo movimento negro como estratégia política e vista atualmente pelo próprio movimento como a maior conquista da luta antirracista no Brasil, como veremos a seguir, tem como objetivo central possibilitar o acesso de jovens negros e pobres a esse espaço de poder e produção de conhecimento que é historicamente branco e elitista: a universidade, especialmente a pública (ALBERTI;

4 Ver, por exemplo, reportagem publicada no jornal El País, edição brasileira, em 23 de dezembro de 2013 (BRUM, 20I3). 
PEREIRA, 2006). A questão das cotas, ou esse "rolê" de jovens negros nas universidades, ainda nos dias atuais, alimenta acalorados embates, como os que foram vistos ao longo das manifestações organizadas por certos setores da sociedade que pediam o impeachment da presidente Dilma Rousseff a partir de 2015 e que, em sua maioria compostas de pessoas brancas de classe média e alta5, elegeram o "fim das cotas para negros nas universidades" como uma de suas bandeiras, ao lado do combate à corrupção e outras demandas.

Ao longo do nosso trabalho de pesquisa de campo para o projeto "Movimento negro na atualidade", no contato com militantes do movimento negro em todas as regiões do país, entre junho e julho de 20I8, "rolezinho", "rolé" ou "rolê", utilizadas para referir-se a eventos ou ações diversas, foram palavras que nos marcaram profundamente. Ouvimos relatos sobre os mais diferentes "rolês" do movimento negro, de norte a sul do país. É possível que a circulação da expressão "rolê" ou "rolezinho" em âmbito nacional tenha se dado em função do alcance midiático dos rolezinhos de São Paulo no final de 2013. Não apenas como uma costura vocabular que se deu de maneira ampla, a ideia de "rolezinho" nos ajuda a enxergar melhor um movimento social em ação em todo o país.

Joel Rufino dos Santos, em seu artigo escrito em I985, verificava nos discursos das lideranças do movimento da época duas definições para o termo "movimento negro". A primeira, que ele chamava de movimento negro "no sentido estrito" e dizia ser "excludente", considerava "movimento negro exclusivamente o conjunto de entidades e ações dos últimos cinquenta anos, consagrados explicitamente à luta contra o racismo" (SANTOS, I985, p. 287). A segunda definição, a de movimento negro no "sentido amplo", que ele afirmava ser “a melhor definição de movimento negro”, é a seguinte:

Todas as entidades, de qualquer natureza, e todas as ações, de qualquer tempo (aí compreendidas mesmo aquelas que visam à autodefesa física e cultural do negro), fundadas e promovidas por pretos e negros. (Utilizo preto, neste contexto, como aquele que é percebido pelo outro; e negro como aquele que se percebe a si.) Entidades religiosas, assistenciais, recreativas, artísticas, culturais e políticas; e ações de mobilização política, de protesto antidiscriminatório, de aquilombamento, de rebeldia armada, de movimentos artísticos, literários e "folclóricos" - toda esta complexa dinâmica, ostensiva ou invisível, extemporânea ou cotidiana, constitui movimento negro. (SANTOS, I985, p. 287).

Para Nilma Lino Gomes, em seu texto publicado em 20I7, corroborando em muito a noção de movimento negro no "sentido amplo", apresentada acima:

Entende-se como movimento negro as mais diversas formas de organização e articulação das negras e dos negros politicamente posicionados na luta contra o racismo e que visam à superação desse perverso fenômeno na sociedade. Participam dessa definição os grupos políticos, acadêmicos, culturais, religiosos e artísticos com o objetivo explícito de superação do racismo e da discriminação racial, de valorização e afirmação, da história e da cultura negras no Brasil, de rompimento das barreiras racistas impostas aos negros e às negras na ocupação dos diferentes espaços e lugares na sociedade. (GOMES, 20I7, p. 24).

5 Ver, entre muitas outras reportagens: Diniz, 20I5. 
A partir do diálogo com autores como Nilma Lino Gomes e Joel Rufino dos Santos, que apontam para a ampliação dos sentidos de "movimento negro", o consideramos aqui como um movimento social que tem como particularidade a atuação em relação à questão racial. Sua formação é complexa e engloba o conjunto de organizações, coletivos e indivíduos que lutam contra o racismo e por melhores condições de vida para a população negra, seja através de práticas culturais, de estratégias político-partidárias, de iniciativas educacionais, de ações no âmbito da saúde etc., demarcando a diversidade e a pluralidade características desse movimento social. Em cada momento da história do Brasil no século XX, de acordo com as diferentes conjunturas sócio-históricas e com as possibilidades de atuação construídas, o movimento social negro organizado possuía características distintas. Contudo, sem dúvida, podemos afirmar a importância da educação, seja como bandeira política seja como estratégia de luta, para a própria constituição desse movimento social, ao menos, desde meados do século XIX. Um bom exemplo, nesse sentido, é o caso da própria criação da Escola de Primeiras Letras, de Pretextato dos Passos e Silva, professor negro que lecionava para crianças negras em I856, na então capital do império, o Rio de Janeiro. A Escola era situada na Rua da Alfândega, 3I3, e, de acordo com o que nos conta Ferreira (20I3, p. 6), foi criada a partir das demandas dos pais e mães de crianças pretas que, por serem seus filhos malquistos nas escolas de brancos, clamavam, preocupados com a formação dos filhos, para que o professor Pretextato promovesse ao menos as instruções primárias junto às suas crianças. Podemos citar ainda experiências desde o início do século XX, como a Escola Progresso e Aurora ${ }^{6}$, as escolas da Frente Negra Brasileira7, o Teatro Experimental do $\mathrm{Negro}^{8}$, dentre muitas outras.

Avançando um pouco mais, ao longo do século XX temos uma série de experiências de organizações negras preocupadas com a educação. No entanto, essa preocupação extrapola os limites do acesso à educação apenas, percebendo-se em meados do século $\mathrm{XX}$ que a luta passa a se constituir também em torno do currículo e do próprio teor qualitativo dessa relação de ensino-aprendizagem ofertado à população em geral e

6 A escola Progresso e Aurora foi criada pela Sociedade Beneficente Amigos da Pátria. "Aberta no dia I3 de maio de I908, era dirigida por Salvador Luís de Paula, um negro ex-ativista do movimento abolicionista" (DOMINGUES, 2008, p. 520).

7 A Frente Negra Brasileira (FNB) foi uma organização negra fundada em I93I e fechada após o golpe de estado com Getúlio Vargas em I937. A educação sempre foi uma das temáticas mais importantes a serem tratadas na FNB. Seus membros acreditavam que a educação era uma ferramenta fundamental para a inserção da população negra na sociedade e também seria através dela que se eliminariam os preconceitos da sociedade e se garantiria a cidadania plena (DOMINGUES, 2008).

8 O Teatro Experimental do Negro (TEN) foi fundado pelo intelectual, artista e militante Abdias Nascimento em I944 na cidade do Rio de Janeiro. A proposta central do TEN era o resgate dos valores da cultura negro-africana e dos indivíduos negros que são degradados dentro da sociedade brasileira. Através da educação e da cultura o TEN buscou alcançar o exercício da cidadania plena por seus atores. Abdias Nascimento acreditava que isso era um ponto essencial e criou salas de aula no TEN para alfabetizar e conscientizar os integrantes. Ver mais em: Nascimento, 2004. 
especificamente à população negra, que passa a se organizar e reivindicar junto ao poder público uma educação que contemple não apenas as bases culturais herdadas da Europa ocidental, o que é hegemônico na tradição educacional brasileira. A luta contra o eurocentrismo nos currículos escolares ganha força nos anos $1970 \mathrm{com}$ a criação do Movimento Negro Unificado (MNU), organização do movimento negro fundada em 1978, que já trazia em sua Carta de princípios demandas como as lutas "pela valorização da cultura negra", por maiores oportunidades de educação e "pela reavaliação do papel do negro na história do Brasil" (PEREIRA, 20I2, p. II3). Identificamos ao longo da pesquisa outros marcos históricos nas lutas do movimento negro brasileiro por e pela educação, como a Marcha Nacional Zumbi dos Palmares, contra o Racismo, pela Cidadania e a Vida, realizada em Brasília em 20 de novembro de I995, quando foi entregue ao então presidente, Fernando Henrique Cardoso, o "Programa para superação do racismo e da desigualdade étnico-racial" no qual a demandas do movimento negro eram apresentadas ao poder público, com destaque na área da educação, como, por exemplo, "Desenvolvimento de ações afirmativas para o acesso dos negros aos cursos profissionalizantes, à universidade e às áreas de tecnologia de ponta" . Outro marco importante foi a participação do movimento negro na preparação e no decorrer da III Conferência Mundial Contra o Racismo, a Discriminação Racial, Xenofobia e Intolerâncias Correlatas, realizada em Durban, na África do Sul, em 200I, quando lideranças do movimento negro conseguiram inserir a frase "cotas para negros nas universidades públicas" no documento oficial levado pela delegação brasileira para a Conferência de Durban (ALBERTI; PEREIRA, 2006). Foi nesse contexto que as primeiras, e ainda tímidas, políticas de ação afirmativa para negros foram adotadas no âmbito do governo federal.

O movimento negro brasileiro, na atualidade, segue dando seus "rolês", nas "pegadas", nas trilhas deixadas pelos passos dados historicamente na luta antirracista por e pela educação, ao mesmo tempo que demonstra uma "pegada" forte na área da educação: com mãos firmes, segue criando, desenvolvendo e promovendo estratégias e ações diversas que fomentam a transgressão racial de espaços físicos e simbólicos de poder, como nas lutas pelo acesso da população negra às universidades e por mudanças nos currículos escolares. Apresentaremos, a seguir, a metodologia de trabalho adotada e alguns dos resultados do projeto de pesquisa sobre o movimento negro em atuação no Brasil. Todo esse quadro de informações articuladas nos aproximará significativamente da compreensão sobre os rolês do movimento negro na atualidade.

\section{Metodologia}

Utilizamos, para o desenvolvimento deste trabalho, um método combinado. A primeira fase de recolhimento de dados consistiu na aplicação de um formulário online, intitulado “Movimento negro na atualidade", enquanto a segunda fase consistiu

9 Ver o documento entregue ao presidente em 1995 e publicado no ano seguinte Por uma política nacional de combate ao racismo e à desigualdade racial: Marcha Zumbi dos Palmares contra o racismo, pela cidadania e a vida (MARCHA Zumbi, I996). 
na realização de entrevistas de história oral ${ }^{\mathrm{To}}$, nas cinco regiões do país, com algumas das pessoas que responderam ao formulário digital.

Na primeira fase, a discussão sobre o que é o "movimento negro", longe de ser ponto pacífico, definição sempre em movimento, influenciou de maneira direta na própria elaboração do formulário apresentado. Nosso objetivo, desde o início, era abarcar as mais diferentes expressões do que se possa compreender como movimento negro. Nesse sentido, contemplamos a possibilidade de respostas sobre indivíduos, entidades, ONGs, instituições públicas, coletivos de estudantes etc., desenvolvendo ações mais institucionalizadas, estratégias de ação mais livres, ou mesmo individuais, dentro de áreas de atuação diversas, tais como: saúde, educação, cultura, luta contra a violência policial, trabalho e geração de renda, legislação, informação, currículos e universidades, religiosidade, empreendedorismo negro, entre outras.

A distribuição do formulário digital foi feita pela internet, circulando por todo o país, via e-mail, aplicativos de mensagem instantânea e redes sociais. Para ampliar a divulgação de nossa ferramenta de pesquisa contamos com a colaboração direta do Geledés Instituto da Mulher Negra ${ }^{\mathrm{II}}$ e do Baobá - Fundo para Equidade Racial ${ }^{\mathrm{T2}}$, entre outras organizações com páginas na internet que compartilharam nosso formulário, em alguns casos mesmo sem um contato direto conosco. Além disso, contamos também com as redes de contatos de militantes do movimento negro. A internet, como ferramenta de comunicação, vem democratizando tanto o acesso à informação como a produção de conteúdos e a emissão polifônica de perspectivas. Nesse cenário, nossa opção em utilizar um formulário digital on-line como instrumento de pesquisa justifica-se pela compreensão de que seria a forma mais efetiva e menos dispendiosa para atingir o maior número de pessoas engajadas na luta antirracista, tendo o maior alcance territorial possível.

O formulário foi estruturado em torno de questões de múltipla escolha e de algumas questões dissertativas. Nosso intuito era tornar o instrumento de pesquisa o mais completo possível, de forma a possibilitar a construção de um mapeamento nacional acerca das características e da atuação do movimento negro na atualidade em nosso país, ao mesmo tempo que pretendíamos mantê-lo simples e fácil de ser respondido, visando à efetividade de sua circulação no universo das mídias digitais e redes sociais. Obtivemos, como resultado, 26I formulários respondidos por militantes antirracistas de todas as regiões do Brasil, entre março e maio de 20I8,

Io As entrevistas de história oral realizadas no ano de 2018 e citadas no presente artigo foram gravadas por Amilcar Araujo Pereira, Amauri Mendes Pereira, Jorge Lucas Maia e Thayara C. Silva de Lima, no âmbito do projeto de pesquisa “Movimento negro brasileiro na atualidade”, realizado pelo Grupo de Estudos e Pesquisas em Educação Antirracista da Universidade Federal do Rio de Janeiro (Gepear/UFRJ), sob a coordenação do prof. dr. Amilcar Araujo Pereira, que contou com o financiamento do Baobá - Fundo para Equidade Racial.

II Geledés Instituto da Mulher Negra é uma organização sem fins lucrativos fundada em I988 que atua em defesa das mulheres e da população negra (GELEDÉS, 20I6a).

I2 O Baobá - Fundo para Equidade Racial, criado em 20II, atua na mobilização de pessoas e recursos no Brasil e no exterior para apoiar projetos que visem à promoção da equidade racial (BAOBÁ, s. d.). 
sendo que $82 \%$ das pessoas que responderam se identificaram como pretas e II,9\% se identificaram como pardas, tendo em vista as categorias de raça/cor do Instituto Brasileiro de Geografia e Estatística (IBGE) - preto, pardo, branco, amarelo e indígena. Cerca de 6I\% dos respondentes são mulheres, configurando uma maioria feminina. Quanto à faixa etária obtivemos um resultado bastante variado, tendo destaque, no entanto, as respostas de pessoas entre 30 e 39 anos, com $28,7 \%$ das respostas, e pessoas entre 50 e 59 anos, com 25,3\% das respostas. Dos respondentes, $72 \%$ relataram fazer parte de alguma instituição/coletivo/organização do movimento negro, enquanto $28 \%$ responderam que fazem militância individual; $93,9 \%$ se identificaram como militantes do movimento negro, enquanto os outras 6,I\%, apesar de se colocarem no cenário da luta antirracista, não se entendem necessariamente como militantes do movimento negro. As respostas vieram, em sua maioria, das regiões Sudeste e Nordeste, e as áreas de atuação mais mencionadas foram educação e cultura.

Na segunda fase da pesquisa optamos pela realização de entrevistas de história oral. Trabalhar com essa metodologia nos abre caminhos e possibilidades de questionamento e análises pluridimensionais. Ouvir alguém narrar sua interpretação a respeito de processos históricos, sociais e políticos nos permite acompanhar os caminhos que cada pessoa trilha e as formas como cada sujeito constrói sua síntese sobre os processos, baseado em suas vivências. $\mathrm{O}$ documento produzido a partir da metodologia da história oral traz especificidades das quais documentos de outra natureza não podem dar conta, visto que há alguns meandros constituintes dos processos e fenômenos sociais que simplesmente não são documentados oficialmente, ficando restritos muitas vezes apenas à memória de quem os viveu. Nesse sentido, ao falar sobre a criação de narrativas e as seleções que essa tarefa implica, Verena Alberti (2004, p. I4) nos fala um pouco sobre a especificidade dessa metodologia:

Uma entrevista de história oral não é exceção nesse conjunto [de registros]. Mas há nela uma vivacidade, um tom especial, característico de documentos pessoais. É da experiência de um sujeito que se trata; sua narrativa acaba colorindo o passado com um valor que nos é caro: aquele que faz do homem um indivíduo único e singular em nossa história, um sujeito que efetivamente viveu - e, por isso, dá vida a - as conjunturas e estruturas que de outro modo parecem tão distantes.

No caso desta pesquisa, o trabalho com a história oral foi fundamental, visto que por meio das entrevistas pudemos acessar essas elaborações tão pessoais que dificilmente conseguiríamos alcançar de outro modo. Buscávamos, grosso modo, conhecer os atores envolvidos no movimento negro na atualidade, como eles se articulam e como estabelecem estratégias de ação e constroem suas trajetórias políticas no movimento social negro. A partir do trabalho no campo e do contato com as narrativas construídas nas entrevistas, os objetivos iniciais foram preenchidos com essa "vivacidade", com esse "tom especial" possibilitado pela metodologia de história oral. Pudemos, a partir disso, tomar contato com eventos, encontros, conversas e ideias-chave, que produziram "viradas" nas vidas de nossos entrevistados e os conduziram à construção de suas trajetórias políticas no movimento negro. Pudemos compreender as conjunturas e elementos que estavam "em jogo" em 
momentos importantes de tomada de decisão ou de desenvolvimento de processos como a organização de coletivos e instituições, bem como os fatos e eventos que influenciaram as pessoas na construção de sua identidade negra. Deparamos também com as questões e temas sensíveis nas vidas dessas pessoas. Fatos e eventos que causaram raiva, alegria, decepção, traumas, tristezas ou outros sentimentos quaisquer importantes em suas trajetórias e que marcaram essas pessoas negativa ou positivamente, tendo sempre em vista a compreensão de como esses elementos influem na construção de suas subjetividades, suas concepções e posições político-ideológicas, como também na formação de suas atuações na militância negra.

As conexões estabelecidas entre elementos pessoais e subjetivos e elementos mais estruturais e objetivos, presentes nas entrevistas que trabalharemos mais adiante, nos possibilitam compreender como essas experiências se constituíram e como elas compõem o complexo cenário em que se desenrola a atuação antirracista do movimento negro na atualidade.

O trabalho de campo foi realizado entre os dias 6 de junho e 20 de julho de 2018. Realizamos um total de 26 entrevistas, somando 30 pessoas entrevistadas e 40 horas e 44 minutos de gravação, em áudio e vídeo. Isso significa uma amostragem de cerca de Io\% do número de formulários preenchidos que recebemos de todo o país. Passamos por sete estados brasileiros, conversando com militantes das cinco regiões do país. $\mathrm{O}$ grupo de pessoas entrevistadas nessa segunda fase foi selecionado a partir da análise dos formulários recebidos, seguindo os seguintes critérios:

I. grau de consistência/coerência nas respostas às questões discursivas;

2. diversidade de perfis e tipos de atuação em organizações/redes/coletivos na militância antirracista;

3. organização e logística para a realização das entrevistas em pelo menos uma capital de estado de cada uma das cinco regiões do Brasil, no período de apenas dois meses, entre junho e julho de 2018.

O primeiro critério utilizado referia-se à coerência e à consistência nas respostas para as seguintes questões discursivas: “O que você entende por 'movimento negro', em poucas palavras?"; "Indique quais são as estratégias e ações desenvolvidas pela entidade/por você?”; “Como se deu a construção da(s) entidade(s) de que faz parte?”; "Cite três das principais instituições/personalidades que inspiram você/sua instituição na luta contra o racismo". Compreendemos que respostas mais estruturadas tinham potencial de indicar ações mais consolidadas na luta antirracista.

O segundo critério referia-se à nossa necessidade de compreender o movimento negro atual na sua diversidade. Nesse sentido, tivemos especial cuidado para selecionar pessoas que trouxessem para a pesquisa experiências geracionais distintas, diferentes áreas de atuação e que tivessem diferentes estruturas organizacionais. Respeitando a diversidade do movimento, alcançamos grupos com características bastante diferentes, tais como redes de ciberativismo e de afroempreendedorismo, coletivos universitários, grupos de estudos ligados à institucionalidade universitária, clubes negros, ONGs, entre outros. 
Por fim, nosso último critério referiu-se à logística para a organização e realização das entrevistas. Buscando compreender o movimento em sua pluralidade, nossa intenção era a de realizar entrevistas nas cinco regiões brasileiras, privilegiando as capitais de estado, por compreender que nessas áreas teríamos condições de, em poucos dias, encontrar um número maior de possíveis entrevistados. Ao fim da aplicação desses critérios acabamos por selecionar as seguintes capitais: Porto Alegre, Belém, Distrito Federal, Recife, Salvador, São Paulo e Rio de Janeiro. As duas últimas regiões, Nordeste e Sudeste, tiveram duas capitais selecionadas pelo fato de que foram as regiões de onde veio o maior número de formulários respondidos. Provavelmente isso se deva ao fato de essas duas regiões reunirem a maior parte das organizações do movimento negro brasileiro. Uma importante característica a ressaltar, referente à segunda fase da pesquisa, é que, apesar de não ter havido uma discrepância muito grande em termos de gênero entre as pessoas respondentes na primeira fase (foram cerca de $60 \%$ mulheres e cerca de 40\% homens), ao aplicar os critérios de seleção de possíveis entrevistados, acima mencionados, a discrepância de gênero ficou evidente: a grande maioria das pessoas entrevistadas foram mulheres. Das 30 pessoas que participaram das 26 entrevistas, 6 eram homens e 24 eram mulheres.

Trabalhamos com roteiros semiestruturados. $\mathrm{O}$ objetivo desse modelo de roteiro é criar eixos para nos ajudar a conduzir a entrevista. Com isso, queremos evidenciar que, longe de propor uma entrevista fechada em questões preestabelecidas, o afloramento de subjetividades e de histórias dentro da história foi sempre incentivado, mesmo que objetivamente não correspondessem às expectativas iniciais de cada entrevista (ALBERTI, 2004). Posto isto, as entrevistas giraram em torno de três eixos temáticos principais. O primeiro deles referia-se às histórias de vida de nossos entrevistados. Nesse eixo favorecíamos o contato com as trajetórias familiares, a infância, a formação escolar e os caminhos pelos quais as questões raciais ganharam destaque na vida dos entrevistados. O segundo eixo girava em torno da atuação mais específica dos indivíduos ou de seus respectivos grupos no movimento negro. Nesse eixo valorizávamos questões acerca das redes/coletivos/organizações que as pessoas entrevistadas compunham, das estratégias por elas desenvolvidas, da estrutura e da manutenção financeira de suas ações ou das próprias organizações. Por fim, o último eixo girava em torno das percepções dos sujeitos sobre o movimento negro e a luta antirracista no Brasil, de forma geral. Aqui se incorporavam questões acerca do estado da arte do movimento negro na atualidade e realizava-se um aprofundamento de questões presentes no formulário preenchido por cada pessoa entrevistada.

Vale ressaltar que a articulação entre essas duas metodologias mostrou-se bastante produtiva. Como será possível perceber, a análise dos dados da primeira fase nos permitiu o acesso a uma espécie de retrato do movimento negro na atualidade, enquanto a segunda fase, com a realização das entrevistas, nos permitiu qualificar esse retrato, mergulhando mais fundo em cada uma das regiões e conhecendo as especificidades da militância desenvolvida em cada cidade por nós visitada. 


\section{OS FORMULÁRIOS}

Uma das questões dissertativas no formulário de pesquisa solicitava às pessoas respondentes que indicassem três personagens históricas (ou atuais) ou organizações como referência para a sua militância na luta antirracista. Nosso objetivo, ao estabelecer essa questão, era o de compreender para onde o movimento negro da atualidade se volta quando está em busca de inspiração. Evidentemente, apenas conhecer as referências não nos oferece um dado conclusivo. No entanto, se levarmos em consideração que só se toma alguém ou alguma organização como referência com base na aprovação ou admiração em relação às suas posturas, pensamentos e/ ou estratégias, a análise dessas referências mostra-se bastante rica em possibilitar um vislumbre da carga de significados e representações que circulam no imaginário desse movimento negro na atualidade. As ONGs Geledés e Criola (s. d.) e as militantes Sueli Carneiro ${ }^{\mathrm{I3}}$ e Djamila Ribeiro ${ }^{\mathrm{I} 4}$ foram as referências mais recorrentemente citadas nos formulários. $\mathrm{O}$ que todas elas têm em comum é a atuação no campo do feminismo negro. Esse fato nos diz muito sobre a força e a importância que o debate sobre gênero e raça vem ganhando no seio da militância negra na atualidade.

Observando todas as respostas, o que ficou evidente foi uma grande diversidade de referenciais escolhidos. De Malcolm X ${ }^{15}$ a Lázaro Ramos ${ }^{16}$ e de Carolina Maria de Jesus ${ }^{17}$ a Marielle Franco ${ }^{18}$, uma série de possibilidades de compreensão de mundo são enunciadas. A importância de rememorar as personalidades negras e suas biografias, visibilizando a história da população negra no Brasil e no mundo, a força do debate da representatividade na mídia, o extermínio da população negra e a radicalização da luta antirracista são apenas alguns traços desse imaginário. Nesse

I3 Sueli Carneiro é filósofa e doutora em educação pela USP. Tem importante atuação no movimento feminista e movimento negro no Brasil, além de ser coordenadora executiva do Geledés Instituto da Mulher Negra.

I4 Djamila Ribeiro é mestre em filosofia política pela Universidade Federal de São Paulo (Unifesp), militante feminista e autora dos livros O que é lugar de fala? (20I7) e Quem tem medo do feminismo negro? (20I8).

I5 Malcolm X (I925-I965) foi um importante militante pelos direitos civis dos negros nos EUA, tendo se tornado uma grande referência no assunto.

I7 "Carolina Maria de Jesus foi cozinheira, empregada doméstica e passou fome. Com dois anos de estudo, escreveu sobre o cotidiano das favelas em contos, poesias e romances” (GELEDÉS, 2OIGb).

I8 "Marielle Franco é mulher, negra, mãe e cria da favela da Maré. Socióloga com mestrado em Administração Pública. Foi eleita vereadora da Câmara do Rio de Janeiro pelo PSOL, com 46.502 votos. Foi também presidente da Comissão da Mulher da Câmara. No dia I4/3/20I8 foi assassinada em um atentado ao carro onde estava” (MARIELLE Franco, s. d.). 
tópico apareceram ainda nomes como Emicida ${ }^{\text {19, }}$, Frantz Fanon ${ }^{20}$, Nilma Lino Gomes ${ }^{2 \mathrm{I}}$ e organizações como o Movimento Negro Unificado (MNU, s. d.) e Unegro (GELEDÉS, 20I8), reforçando o caráter diverso de referenciais.

Diversidade é uma característica importante do movimento negro historicamente, como já foi dito. E essa diversidade de referências selecionadas pelos militantes atuais vem a corroborar essa afirmação. Em outros tempos o acesso à informação era bastante reduzido. Raros são os casos de entrevistas com militantes históricos que não narram as dificuldades em conseguir textos contendo informações acerca da luta e dos movimentos negros em outras partes do mundo ou ainda em outros tempos (ALBERTI; PEREIRA, 2007). A internet, como fenômeno contemporâneo, potencializou a circulação desses referenciais. Qualquer conteúdo produzido na rede fica disponível para todo o mundo em tempo real. O fluxo de informações favorece a circulação de conhecimento, e assim sujeitos antes invisibilizados podem ganhar espaço, compondo o quadro de referências para as novas gerações de militantes.

Se, de maneira geral, conhecemos um pouco da diversidade de referências indicadas por esse movimento negro atual, é preciso compreender também um pouco como a militância olha para o passado da luta antirracista e como entende a conjuntura atual em relação a essa luta. Nesse sentido, colocamos no formulário digital duas questões de múltipla escolha, nas quais cada respondente poderia escolher quantas opções desejasse. As perguntas foram as seguintes: "Na sua opinião, qual(ais) a(s) conquista(s) mais significativa(s) da luta antirracista no Brasil?" e "Na sua opinião, qual(ais) a(s) luta(s) mais urgente(s) da população negra na atualidade?”.

Quanto às principais conquistas históricas alcançadas pelo movimento negro, $89,7 \%$ dos respondentes colocaram em primeiro lugar a conquista das cotas para negros nas universidades públicas. Esse é, sem dúvida, um debate que tem mobilizado boa parte da sociedade brasileira desde o início do século XXI, e essa conquista, decorrente da luta antirracista, entre outras coisas, já trouxe questões significativas sobre os currículos e as disputas epistemológicas travadas em torno da produção de conhecimento nas universidades.

A segunda conquista mais selecionada, por $78,2 \%$ dos respondentes, foi a criação da Lei Io.639/03 (BRASIL, 2003), que tornou obrigatório o ensino de história e cultura afro-brasileiras e africanas nas escolas de todo o Brasil, incidindo de maneira direta sobre o processo de construção dos currículos, tanto na educação básica quanto no ensino superior, espaço no qual são formados os professores que atuarão nas escolas do país. Alguns reflexos dessa conquista também poderão

I9 Rapper, cantor e compositor brasileiro (EMICIDA, s. d.).

20 Frantz Fanon (I925-I96I) foi um filósofo e psiquiatra martinicano. Seus livros mais conhecidos no Brasil são Peles negras, máscaras brancas (I952) e Os condenados da terra (I96I).

2I Nilma Lino Gomes é doutora em Antropologia Social pela Universidade de São Paulo (USP) e professora da Faculdade de Educação da Universidade Federal de Minas Gerais (UFMG). Foi ministra da Secretaria de Políticas de Promoção da Igualdade Racial (Seppir) e do Ministério das Mulheres, da Igualdade Racial, da Juventude e dos Direitos Humanos entre 2015 e 2016. 
ser vislumbrados abaixo. Essa legislação, juntamente com a entrada, em número cada vez maior de jovens negros nas universidades, vem intervindo de forma significativa nas disputas em torno dos currículos escolares e universitários, e na educação de maneira geral. Em nossa pesquisa observamos a existência de muitos coletivos de estudantes negros e de muitas ações antirracistas que se desenvolvem atualmente e são ligadas ao mundo universitário.

Em relação às lutas mais urgentes para a população negra na atualidade, a que mais se destacou, com 83,I\% das respostas, foi a luta pelo fim da violência policial contra a juventude negra. Aqui podemos observar a permanência de um debate e de uma demanda de forma sólida através do tempo. A luta política contra o chamado "genocídio da população negra" não é nova e nem é uma característica brasileira. Ao contrário, essa é uma das principais características do movimento negro transnacional atualmente, que tem expoentes como o Black Lives Matter (s. d.) e o Reaja ou Será Morto(a) (s. d.). Ana Flauzina e João Vargas nos lembram que

[...] já em I95I William Patterson e o Congresso dos Direitos Civis (Civil Rights Congress) formulavam We Charge Genocide, denunciando o atentado ao direito de existência da coletividade negra nos Estados Unidos. No Brasil, em I978, Abdias do Nascimento publicava [o seu livro] O genocídio do negro brasileiro, alertando para destino semelhante relegado ao povo negro no país. (FLAUZINA; VARGAS, 20I7, p. 5).

Ainda em I978, o Movimento Negro Unificado (MNU) foi criado, entre outras coisas, a partir da mobilização em torno do assassinato de um jovem negro dentro de uma delegacia de polícia da cidade de São Paulo (PEREIRA, 20I3). Naquele mesmo ano, quando o MNU lançava sua Carta de princípios, um dos pontos denunciados já era a "permanente repressão, perseguição e violência policial". Os recentes dados do Mapa da violência (WAISELFISZ, 20I6) indicam um estado de grande letalidade contra a juventude negra. Segundo a Campanha "Vidas negras", encabeçada pela Organização das Nações Unidas (ONU) no Brasil:

[...] de cada mil adolescentes brasileiros, quatro vão ser assassinados antes de completar I9 anos. Se nada for feito, serão 43 mil brasileiros entre os I2 e os I8 anos mortos de 2015 a 202I, três vezes mais negros do que brancos. Entre os jovens, de I5 a 29, nos próximos 23 minutos, uma vida negra será perdida e um futuro cancelado. (ONUBR, 20I7).

Um dos conceitos apresentados, nessa campanha da ONU, para compreender tamanha letalidade é a "filtragem racial". Em um dos vídeos o conceito é explicado: "é quando uma pessoa negra é injustamente escolhida pela cor. Escolhida como suspeita quando está parada, e como criminosa quando está correndo. Jovens negros e negras são as principais vítimas da violência” (ONUBR, 20I7). Segundo a campanha da ONU, um dos principais responsáveis pelo que muitos militantes têm chamado de "genocídio da juventude negra” é a ação do próprio Estado, através de seu aparato policial.

Na segunda posição, como luta mais urgente da população negra, com 75,I\% das respostas, aparece a luta pela efetiva implementação da Lei Io.639/03 (BRASIL, 2003). É interessante notar que essa lei, específica da área da educação, aparece 
em segundo lugar tanto como conquista histórica quanto como luta mais urgente para o movimento, o que demonstra, antes de qualquer coisa, a importância, para o movimento negro, das lutas em torno da educação e mais especificamente dos currículos escolares, tanto atual quanto historicamente. A já citada Carta de princípios do MNU também trazia a luta "pela reavaliação do papel do negro na história do Brasil” como uma de suas principais demandas, ainda em I978.

O processo de implementação da Lei Io.639/03 tem mobilizado toda uma estrutura educacional que, ao longo de décadas, ignorou ou negligenciou a relevância da história e das memórias da população negra. Essa legislação fomenta o desenvolvimento de novos materiais didáticos, a produção de conhecimento e conteúdos acerca da história e cultura negra, a visibilização de biografias de personagens negras, o que resulta, inclusive, na maior circulação de referenciais, na reforma dos currículos das licenciaturas, visando a uma formação antirracista para as novas gerações de professores, e na presença de conteúdos voltados para as relações raciais tanto em concursos públicos como no Exame Nacional do Ensino Médio (Enem). Como se pôde observar até aqui, são muitos os "rolês" do movimento negro na área da educação.

Em relação ao movimento negro na atualidade, vale ressaltar algumas características evidenciadas nas respostas ao formulário da pesquisa: $72 \%$ dos respondentes fazem parte de alguma organização/entidade/coletivo do movimento negro. Dentre esses, $73 \%$ declaram que sua organização não é ligada a nenhuma rede ou fórum, seja local, seja nacional ou de amplitude internacional. O que nos revela que a grande maioria das organizações representadas entre os respondentes atua de maneira isolada. Quanto à estrutura organizacional de cada entidade, 45,6\% entendem sua organização como horizontais e colaborativas, ao passo que em I4,6\% das organizações há uma diretoria eleita e um conselho deliberativo.

A militância antirracista articulada a outras lutas sociais também foi uma característica evidente no movimento negro na atualidade. Dos $87,7 \%$ que declararam essa atuação articulada, $85 \%$ atuam em articulação ao movimento de mulheres; 56,2\% também atuam na luta contra a homofobia. Quanto à manutenção financeira dessas ações, 49\% indicaram que não possuem nenhum tipo de financiamento externo; $33 \%$ se mantêm com doação de membros; enquanto I9\% se mantêm com apoio de editais públicos ou privados. A internet, ainda que indicada como importante veículo para a ação na luta antirracista por $97,7 \%$ dos respondentes, ainda não é uma ferramenta significativa para a manutenção financeira dos movimentos e ações antirracistas, tendo como principais finalidades a divulgação e mobilização para ações presenciais e a divulgação de informações sobre as ações realizadas.

Um dado bastante impactante, presente nas respostas ao formulário, foi a informação de que para $86,6 \%$ dos respondentes há mulheres negras em posição de liderança nas (ou à frente das) organizações ou nas ações antirracistas. Esse dado é bastante relevante, sobretudo, para que consigamos compreender a segunda fase de nossa pesquisa, quando ficou ainda mais evidente, nas entrevistas realizadas, o protagonismo feminino na luta antirracista empreendida na atualidade em nosso país. 


\section{Análise das entrevistas}

Um dos objetivos centrais de nossa investigação foi tentar compreender o que os militantes pensam sobre o que é o movimento negro na atualidade, inspirados em Joel Rufino dos Santos, que, em seu artigo escrito em I985, afirmava que "movimento negro é, antes de mais nada, aquilo que seus protagonistas dizem que é movimento negro" (SANTOS, I985, p. 287). As respostas a esse questionamento foram múltiplas, tendo em vista que cada perspectiva, individual ou institucional, sofre grande influência dos desafios encontrados em cada frente de atuação e em cada contexto histórico e social. Apesar dessa multiplicidade, há pontos e narrativas gerais a esse respeito que nos parecem bastante interessantes. A compreensão desse movimento como um movimento diverso e descentralizado é evidente. Alguns militantes inclusive têm dificuldade em defini-lo frente à diversidade de ações e articulações que se realizam a partir de pequenas coletividades ou até a partir da ação de indivíduos, o que diverge, em muitos casos, da lógica da fundação e manutenção de instituições, que foi uma forma histórica de organização desse movimento social. Jéssyca Silveira ${ }^{22}$, do Rio de Janeiro, nos informa sobre suas percepções em torno do que é e como se articula o movimento negro na atualidade:

O que é o movimento negro no fim das contas? São esses movimentos micro. Antes era mais macro, você estar em uma instituição, em uma associação, em uma organização, não sei... Hoje em dia é justamente essa pluralidade. Um grupo de Facebook, por que não? É só um grupo de Facebook? É só um grupo de Facebook, mas é um p[...] grupo de Facebook, isso significa muita coisa.

Aí tem a questão de ativista versus militante também. Tem muito ativista, mas não necessariamente muitos militantes. Muito ativista de internet, muita gente que fica debatendo, mas a prática não corresponde tanto assim às vezes. Então acho muito complexo definir nessa conjuntura.

[...] Eu não me vejo necessariamente como parte do movimento negro, justamente por não conseguir determinar o que é o movimento negro hoje e por eu acreditar que ele é tão plural e que ele está em tantas pequenas coisas. Eu sou parte dele, mas ao mesmo tempo eu estou só23.

O enfoque na ação individual como algo que pode gerar impactos significativos também nos chamou a atenção na fala de Jéssyca, principalmente quando ela diz, referindo-se ao modo como compreende sua vinculação ou não ao movimento negro, partindo aparentemente de uma noção desse movimento como algo ligado a estruturas organizacionais coletivas: "Eu sou parte dele mas ao mesmo tempo estou só”. Ao mesmo tempo que há identificação com uma totalidade, uma movimentação mais geral de ações que, por mais diversas que sejam, caminham em um mesmo sentido, o do combate ao racismo, há também, por outro lado, o reconhecimento

22 Jéssyca Silveira, 26 anos, é bacharel e licenciada em História pela UFRJ. Jéssyca é também fundadora da RAP - Rede de Afro Profissionais (<https://www.redeafroprofissionais.com.br, acesso em 2I/9/20I8).

23 A entrevista com Jéssyca Silveira foi realizada no Instituto de História da UFRJ em 8/6/20I8. 
de uma especificidade individual por não fazer parte de nenhuma instituição com estatuto, sede etc., mas sem deixar de gerar efeitos positivos para a construção dessa mesma luta antirracista. Essa narrativa corrobora os resultados encontrados nos formulários respondidos por militantes de todas as regiões do país, que, como vimos, demonstram uma grande quantidade de indivíduos e de coletivos ou pequenos grupos desvinculados de estruturas organizacionais. Caminhando nesse mesmo sentido, a executiva Luana Teófillo ${ }^{24}$, de São Paulo, faz suas considerações:

Tem esses grandes movimentos: Unegro, Uneafro [s. d.], Movimento Negro Unificado etc., e outros coletivos, que atuam na estrutura. São os que entram com ações judiciais, que fazem denúncias, o que é muito importante, porque a sociedade é feita de leis. Com a internet você tem toda uma militância. Você tem um primeiro nível de militantes, pessoas como eu, que têm seus coletivos, que têm suas organizações e estão atuando real, estão denunciando, estão indo para cima, estão dando a cara, se levantando, mas que não estão dentro de uma estrutura organizada. Mesmo que eu tenha o coletivo Efigênias, a atuação ainda é muito individualizada, a gente ainda não tem uma estrutura para muitas coisas. [...] [Nessa segunda camada] militantes. Pessoas que estão de fato trabalhando, que participam dos eventos. Aqui em São Paulo é um grupo bem consistente, então você acaba conhecendo as pessoas. São pessoas que vão lá, fortalecem, participam. No trabalho às vezes é uma liderança, faz as escolhas, pratica o black money. É essa grande massa que acaba empurrando, porque os movimentos organizados acabam sendo poucos.

Aí você tem uma terceira camada, que é um pouquinho mais diluída de ativistas ou pessoas que são simpáticas à causa, que absorvem, que vão pegando. De repente não têm uma atuação direta, mas aprendem, consomem conteúdo, aí já tem ali uma visão melhor para educar o filho ou mesmo um professor, que consegue ter outras formas de atuação. Nessa parte de baixo ainda tem muitas pessoas brancas também que têm interesse, que querem... muitas não! Tem um ou outro ali, que quer ${ }^{25}$.

Luana nos traz um ponto de vista que aponta em um sentido muito parecido ao que Jéssyca aponta, mas traz ainda outros elementos para compor esse complexo quadro. Ela categoriza a atuação do movimento negro em três camadas: a primeira é a institucional, como os exemplos citados acima; na segunda camada estariam os coletivos e mesmo indivíduos que têm uma agenda de atuação e certo nível de articulação, mas que não têm a mesma institucionalidade dessas entidades históricas do movimento negro; e a terceira é de "ativistas" simpáticos à causa, mas que não se envolvem em ações diretas.

24 Luana Teófillo é fundadora do coletivo Efigênias (s. d.) e do Painel de Consumidores Afro-brasileiros (s. d).

25 A entrevista com Luana Teófillo foi realizada no hotel La Residence Paulista, em São Paulo, no dia I7/7/20I8. 
Tatiana Nascimento ${ }^{26}$, poeta brasiliense, apresenta sua perspectiva acerca da distinção entre o movimento negro histórico, organizado em instituições como o MNU, a Unegro e afins e as formas atuais de organização da militância. A esse respeito, ela diz o seguinte:

Eu fico vendo que a gente está com pelo menos dois modelos de luta e ação que estão conflitantes e que têm a ver com raízes metodológicas distintas. De um lado tem a movimentação tradicional de organizações negras, tradicionais também, que fazem o que a gente aprendeu como ativismo negro e que está relacionado com demandas por políticas públicas para a população negra e acesso ao mundo dos direitos. Incluir a negritude dentro do banquete dos direitos humanos. Tem isso e essa movimentação mais recente que tem a ver com afirmar existências individualmente de forma... deslumbrante. Estou pensando mais no rolê da geração tombamento. Não sei se é porque estou muito envolvida nesse rolê, mas eu vejo isso crescendo muito e as pessoas se articulando em torno disso. Coletivos, organizações, eventos... ${ }^{27}$.

Tatiana, como podemos observar, fala das diferenças nas formas de conceber a atuação das pessoas nos diversos "rolês" do movimento. Há uma ideia de que, apesar de haver um objetivo comum, o combate ao racismo, esses combatentes bebem em fontes diferentes e muitas vezes pensam a construção da luta por perspectivas diferentes e, em alguns casos, como nos disse Tatiana, até conflitantes. É importante deixar evidente que a dimensão do conflito não necessariamente significa um enfraquecimento ou até desarticulação do movimento negro. Para alguns entrevistados, sim, essa pluralidade atrapalha. Mas, para outros, a pluralidade é justamente a grande força do movimento negro na atualidade.

É curioso observar que Jéssyca, Luana e Tatiana mobilizam os sentidos de "militância" e "ativismo" de maneira fluida, remetendo-se diretamente às formas de organização dos sujeitos que realizam a luta antirracista, mas de forma que nem sempre as categorias apresentadas guardam o mesmo significado. Jéssyca e Luana localizam o "ativista" como um sujeito que está à margem da militância organizada, enquanto Tatiana, num sentido oposto, caracteriza o ativismo relacionando-o com as demandas por políticas públicas, fruto da ação de movimentos mais institucionalizados. Apesar de percepções distintas quanto às categorias, compreendemos que, ao mobilizar tais sentidos, as entrevistadas apontam para a compreensão do movimento negro no "sentido amplo", assim como Joel Rufino dos Santos, já citado, e Nilma Lino Gomes também faz no trecho a seguir ao considerar a atuação individual de "negras e negros em movimento" no âmbito da luta antirracista:

26 Tatiana Nascimento é uma poeta brasiliense, diretora da Padê, editora que publica literatura de pessoas pretas e LBTs. Tatiana é também uma das fundadoras da Palavra Preta, mostra de música, literatura e produções audiovisuais de mulheres pretas.

27 A entrevista com Tatiana Nascimento foi realizada na casa da entrevistada, em Brasília, no dia 7/7/20r8. 
Articulados às práticas e intervenções do Movimento Negro e sendo reeducados direta ou indiretamente por ele é possível encontrar, também no Brasil, vozes e corpos negros anônimos que atuaram e ainda atuam na superação do racismo e na afirmação da identidade, dos valores, do trabalho, da cultura e da vida da população negra, presentes no cotidiano da sociedade brasileira. São as negras e os negros em movimento: artistas, intelectuais, operários e operárias, educadoras e educadores, dentre outros, ou seja, cidadãs e cidadãos que possuem uma consciência racial afirmativa e lutam contra o racismo e pela democracia, mas não atuam necessariamente em uma entidade ou organização específica. Todos são, de alguma forma, herdeiros dos ensinamentos do Movimento Negro, o qual, por conseguinte, é herdeiro de uma sabedoria ancestral. (GOMES, 20I7, p. I8).

Quantos aos “ativistas que debatem na internet”, sobre os quais falava Jéssyca, os "simpáticos à causa que vão pegando, que não tem uma ação direta, mas aprendem”, sobre os quais falava Luana, e quanto às "vozes e corpos negros que lutam contra o racismo, mas não em uma entidade", "negras e negros em movimento", conforme nos diz Nilma Gomes, antes de representar um ponto negativo, a existência desses sujeitos é possível graças à força da circulação da cultura de luta antirracista, reeducando a sociedade, a partir da luta do movimento negro, como compreenderemos melhor a seguir.

O que temos chamado de "cultura de luta antirracista" parte do diálogo com autores como Amilcar Cabral, guineense-cabo-verdiano, uma das maiores lideranças revolucionárias africanas no século XX, e Stuart Hall, teórico dos estudos culturais, de origem jamaicana e radicado na Inglaterra. Para Amilcar Cabral (I974, p. I37), referindo-se à luta anticolonialista na África de meados do século XX, "a luta não é apenas um fato cultural, mas também um fator de cultura”. Nesse sentido, o autor/ revolucionário compreende que o processo de luta política também produz cultura, o que potencialmente influencia na construção de identidades e subjetividades por parte de atores sociais diversos a partir do contato com a luta política em si. Hall (I997, p. I6) compreende que "cada instituição ou atividade social gera e requer seu próprio universo distinto de significados e práticas - sua própria cultura”. Ao observarmos a luta política enquanto atividade social, retomamos aqui o ponto de contato com Cabral. Isso significa dizer que a luta produz uma série de códigos e significados próprios e que vai afetando os diversos sujeitos a partir do contato com ela, tendo em vista a cultura como um processo, sempre em movimento, repleto de negociações, hibridizações e "entrelugares”, como diria Homi Bhabha (I998). Pensando na luta política como fato cultural e também fator de cultura é que nos voltamos em direção ao movimento negro. Se a luta produz cultura, o movimento negro, a partir dos códigos e significados produzidos na/pela luta antirracista, também produz o que chamamos de cultura de luta antirracista.

É a circulação dessa cultura de luta antirracista que possibilita a adesão de sujeitos como a Jéssyca, que, mesmo sem se identificar necessariamente com qualquer instituição mais estruturada do movimento negro, sente-se parte desse movimento. É ainda a partir desse prisma que compreendemos a reflexão de Luana de que os efeitos da luta antirracista se estendem para além dos indivíduos e coletividades que atuam diretamente na produção dessa luta. Mesmo que algumas pessoas não atuem nesse movimento social 
diretamente, o contato com a cultura de luta antirracista educa/reeduca e possivelmente gera mudanças na maneira como essas pessoas se colocam frente às questões ligadas ao racismo, sejam elas negras, brancas, amarelas ou indígenas.

A ideia de que esse movimento é muito plural e de que esses rolês do movimento negro estão acontecendo de forma ampla, atingindo muitos setores da sociedade e funcionando tanto pela via institucional quanto pelas pequenas iniciativas, até mesmo individuais, é bastante recorrente. Sobre isso Gabrielle Conde ${ }^{28}$, militante na cidade de Recife, nos diz o seguinte: "Eu acho importantíssimo que ele [o movimento negro] tenha se capilarizado e que a gente consiga, como um rio, como água do rio, se encaixar em pedras e ir encontrando alternativas para atuar"29.

Pensando nessa multiplicidade de frentes encampadas pelo movimento negro atual, tivemos notícias de uma série de rolês em diferentes áreas da luta antirracista, em diversos contextos sociais. Todas essas frentes demandam suas próprias estratégias para permitir a transgressão de espaços de poder. Os rolês do movimento negro atualmente só são possíveis porque historicamente houve uma série de estratégias traçadas por indivíduos e coletividades para adentrar espaços que oferecem resistência não apenas às pessoas negras, ou à temática da história e cultura afro-brasileira e africana, mas também a todo o campo simbólico em torno de ambos. Assim sendo, percebemos ao longo da pesquisa que, dentre as diferentes estratégias e ações desenvolvidas pelo movimento negro brasileiro na atualidade, uma das preocupações fundamentais ao pensar a efetivação desses rolês gira em torno das formas encontradas pelos militantes, em suas diferentes frentes de atuação, para entrar em espaços importantes para a viabilização e o desenvolvimento da luta antirracista. Trabalhamos tentando compreender quais são os rolês do movimento e como eles impactam os espaços em que se desenvolvem.

Nesse sentido, optamos por destacar o rolê do movimento negro brasileiro na atualidade pela área da educação. Inclusive, há que se destacar que esse não é um fenômeno novo. As lutas do movimento negro no âmbito da educação, como já foi dito, vêm de longe - os séculos XIX e XX são repletos dessas experiências, tanto de reivindicações pela inclusão da população negra nos sistemas de educação formal como de iniciativas em torno das demandas por mudanças nos currículos escolares (GONÇALVES; SILVA, 2000; PEREIRA, 20I2). Entretanto, as recentes conquistas, já apontadas quando nos detivemos na análise dos formulários, como a reserva de cotas para estudantes negros e a Lei Io.639/03, criaram uma série de novas demandas, preocupações e ações bastante características do movimento negro na atualidade.

Pensando a partir do ponto em que consideramos as legislações como "estruturantes" da vida social, conforme compreende a entrevistada Luana, podemos localizar a Lei Io.639/03 como importante nesse sentido. Assim sendo, sua tradução na prática cotidiana tem sido uma das grandes questões que mobilizam o debate em torno das relações raciais no Brasil, sobretudo no campo da educação. Essa tradução

28 Gabrielle Conde é capoeirista, arte-educadora e foi candidata a deputada federal em 20I8, pelo estado de Pernambuco.

29 A entrevista com Gabrielle Conde foi realizada na casa da entrevistada em Olinda (PE), no dia 9/7/20I8. 
vai depender não necessariamente das ações das organizações do movimento negro mais institucionalizadas, mas também, e sobretudo, das formas através das quais a diversidade de sujeitos é afetada pela cultura de luta antirracista, em suas diversas frentes de atuação, e, a partir daí, pela forma como essas organizações se apropriam da realidade que as cerca no sentido de criar estratégias que viabilizem uma educação antirracista (LIMA, 20I8).

\section{CONSIDERAÇõES FINAIS}

Nosso principal objetivo, neste artigo, foi apresentar e discutir alguns resultados de nossa pesquisa sobre o movimento negro na atualidade. Foi possível demonstrar a pluralidade de frentes de atuação nas quais o movimento negro tem operado, destacando-se a atuação na área da educação, nas "pegadas" destacadas desde o título. Afinal de contas, como se diz com frequência na luta antirracista, Nossos passos vêm de longe $~^{30}$. Essa conhecida frase aponta para o que pretendemos expressar quando falamos sobre o aspecto histórico das lutas desse movimento social na área da educação. Como foi possível observar, as duas conquistas históricas consideradas como as mais importantes pelo movimento negro em atuação são justamente conquistas na área da educação: as cotas raciais que, neste século, permitiram o acesso de pessoas negras às universidades públicas no Brasil como nunca antes; e a Lei Io.639/03, que tornou obrigatório o ensino de história e cultura da África e dos afrodescendentes nas escolas de todo o país.

A pesquisa nos trouxe ainda uma série de outras questões e dados para reflexão sobre a atuação do movimento negro na atualidade, como o afroempreendedorismo, as militâncias por meio da arte, as discussões em torno da capilarização e da pulverização do movimento negro, entre outras, as quais, por questões práticas, deverão ser abordadas em trabalhos posteriores.

De maneira geral pudemos perceber que os rolês na atualidade são plurais e têm chegado a espaços historicamente de difícil acesso para o movimento negro ou mesmo para a população negra de modo geral, como, por exemplo, as universidades. Essa entrada, em grande medida, é facilitada pela circulação da cultura de luta antirracista produzida a partir da ação do próprio movimento negro. O que inicialmente nos parece um paradoxo constitui-se, de certa maneira, num movimento circular. A cultura de luta antirracista é produzida a partir da luta da militância negra ao mesmo passo que, num movimento dialógico, essa cultura impacta a sociedade, afeta novos sujeitos e também é afetada pelas dinâmicas sociais, produzindo novos códigos e significados.

O fato é que, nessa dança entre a luta antirracista e o universo de significados que surgem a partir dela, não podemos ignorar o evidente protagonismo feminino. Ao analisar as entrevistas realizadas é notória a predominante presença de

30 A frase é parte do título de um livro organizado por Jurema Werneck, Maisa Mendonça, Evelyn C. White $(O$ livro da saúde das mulheres negras: nossos passos vêm de longe), que foi publicado no ano 2000. Posteriormente foi título de outros trabalhos de Jurema Werneck, cofundadora da ONG Criola, já mencionada. A frase ganhou popularidade nos últimos anos entre a militância negra no Brasil. 
mulheres. Como vimos na parte inicial deste artigo, as referências mais citadas nas respostas ao formulário de pesquisa foram mulheres negras e organizações de mulheres negras, mesmo tendo cerca de $40 \%$ de homens entre os militantes respondentes; $86,6 \%$ das pessoas responderam que há mulheres negras na liderança ou na direção de suas organizações.

O que se torna evidente aqui é o seguinte: uma vez que as mulheres protagonizam a luta antirracista de maneira geral, e não apenas no campo do feminismo negro, é a partir dessa luta que se produzem os novos códigos e significados que alimentam a cultura de luta antirracista que, por sua vez, em movimento, afeta os novos sujeitos, espraiando-se na sociedade. Esse movimento põe em questão um ponto fundamental, o da representação, sobre o qual não avançaremos aqui neste artigo, mas que consideramos um importante resultado da nossa pesquisa e que desenvolveremos melhor em futuros artigos. Ainda assim, deixamos aqui uma questão/provocação e convidamos a refletir conosco: nesse amplo e diverso "rolê", levando em consideração a forte "pegada" feminina na organização e realização da luta antirracista reeducando a sociedade de diversas formas, ainda é possível falarmos em "movimento negro", no masculino? Está lançada a questão.

\section{SOBRE OS AUTORES}

AMILCAR ARAUJO PEREIRA é professor associado da Faculdade de Educação, vice-coordenador do Programa de Pós-Graduação em Educação da Universidade Federal do Rio de Janeiro (PPGE/UFRJ), coordenador do Grupo de Estudos e Pesquisas em Educação Antirracista (Gepear/UFRJ) e bolsista Jovem Cientista do Nosso Estado/Faperj.

E-mail: amilcarpereira@hotmail.com https://orcid.org/oooo-oooI-778I-6882

JORGE LUCAS MAIA é mestrando em Educação no PPGE/UFRJ e integrante do Gepear/UFRJ.

E-mail: jmjorgemaia@gmail.com https://orcid.org/0000-0002-5565-6053

THAYARA CRISTINE SILVA DE LIMA é doutoranda em Educação no PPGE/UFRJ e integrante do Gepear/ UFRJ.

E-mail: thaycsl89@gmail.com

https://orcid.org/o0oo-0002-5137-2686 


\section{REFERÊNCIAS}

ALBERTI, Verena. Ouvir contar: textos em história oral. Rio de Janeiro: Ed. FGV, 2004.

; PEREIRA, Amilcar A. A defesa das cotas como estratégia política do movimento negro contemporâneo. Estudos Históricos, Rio de Janeiro, v. I, n. 37, 2006, p. I43-I66.

(Org.). Histórias do movimento negro no Brasil: depoimentos do CPDOC. Rio de Janeiro: Pallas; CPDOC/FGV, 2007.

BAOBÁ - Fundo para Equidade Racial. Fundo Baobá - Lutar em prol da Equidade Racial. s. d. Disponível em: 〈https://baoba.org.br/fundo-baoba-2>. Acesso em: I9 set. 2019.

BHABHA, Homi K. O local da cultura. Belo Horizonte: Ed. UFMG, I998.

BLACK Lives Matter. The Black Lives Matter Global Network is a chapter-based, member-led organization whose mission is to build local power and to intervene in violence inflicted on Black communities by the state and vigilantes. s. d. Disponível em: 〈https://blacklivesmatter.com/about $\rangle$. Acesso em: Io set. 2018.

BRASIL. Presidência da República. Casa Civil. Subchefia para Assuntos Jurídicos. Lei nº Io.639, de 9 de janeiro de 2003. Altera a Lei ํㅜㅇ.394, de 20 de dezembro de I996, que estabelece as diretrizes e bases da educação nacional, para incluir no currículo oficial da Rede de Ensino a obrigatoriedade da temática "História e Cultura Afro-Brasileira", e dá outras providências.

BRUM, Eliane. Os novos "vândalos" do país. El País, 23 dez. 2003. Disponível em: <https://brasil.elpais. $\mathrm{com} / \mathrm{brasil} / 20 \mathrm{I3} / \mathrm{I2} / 23 /$ opinion/I387799473_348730.html $>$. Acesso em: 3I ago. 2018.

CABRAL, Amílcar. Guiné-Bissau: nação africana forjada na luta. Lisboa: Nova Aurora, I974.

CRIOLA. Quem somos. s. d. Disponível em: 〈https://criola.org.br/?onepage=quem-somos $>$. Acesso em: 3I ago. 2018.

DINIZ, Maiana. Manifestantes contra o governo são brancos e de alta renda, aponta pesquisa. Empresa Brasil de Comunicação - EBC, I8 ago. 20I5. Disponível em: <http://www.ebc.com.br/noticias/20I5/o8/ pesquisas-revelam-retrato-social-e-racial-de-manifestantes $\rangle$. Acesso em: 3I ago. 2018.

DOMINGUES, Petrônio. Um "templo de luz”: Frente Negra Brasileira (I93I-I937) e a questão da educação. Revista Brasileira de Educação, v. I3, n. 39, 2008, p. 5I7-534. http://dx.doi.org/I0.I590/SI4I324782008000300008.

EFIGENIAS. Disponível em: <http://www.efigenias.com.br/>. Acesso em: 2I set. 2018.

EMICIDA. Bio. Por Vinicius Felix. Disponível em: 〈http://www.emicida.com/bio >. Acesso em: 2I set. 2018.

FANON, Frantz. (I952). Peles negras, máscaras brancas. Salvador, EDUFBA, 2008. . (I96I). Os condenados da terra. Juiz de Fora. Ed. UFJF, 2005.

FERREIRA, Higor Figueira. O protagonismo social de professores negros da corte na produção de experiências escolares independentes (Rio de Janeiro, século XIX). In: SIMPÓSIO NACIONAL DE HISTÓRIA, 25., Conhecimento histórico e diálogo social. Anais... Associação Nacional de História -ANPUH, Natal, 2013.

FLAUZINA, Ana L. P.; VARGAS, João H. C. (Org.) Motim: horizontes do genocídio antinegro na Diáspora. São Paulo: Brado Negro, 20I7.

GELEDÉS Instituto da Mulher Negra. Missão institucional. Io de abril, 20I6a. Disponível em: <https:// www.geledes.org.br/geledes-missao-institucional >. Acesso em: 2I set. 2018.

. Negra, ex-catadora e "favelada". Você conhece a escritora mineira lida em I/ línguas?. Do Brasileiros. 3 de maio, 20I6b. Disponível em: <https://www.geledes.org.br/negra-ex-catadora-e-faveladavoce-conhece-escritora-mineira-lida-em-I4-linguas $\rangle$. Acesso em: 2I set. 2018.

. Unegro: 30 anos de luta pela igualdade racial, de gênero e de classe. Por Mônica Custódio do 
Vermelho. I8 de julho, 20I8. Disponível em:<https://www.geledes.org.br/unegro-30-anos-de-luta-pela-igualdade-racial-de-genero-e-de-classe $>$. Acesso em: 2 set. 2018.

GOMES, Nilma Lino. O Movimento Negro educador: saberes construídos nas lutas por emancipação. Petrópolis: Vozes, 2017.

GONÇALVES, Luiz Alberto Oliveira; SILVA, Petronilha Beatriz Gonçalves. Movimento negro e educação. Revista Brasileira de Educação, n. I5, set.-dez./2000, p. I34-I58.

HALL, Stuart. A centralidade da cultura: notas sobre as revoluções culturais do nosso tempo. Educação er Realidade, Porto Alegre, v. 22, n. 2, jul./dez. I997, p. I5-46.

LIMA, Thayara C. S. de. A cultura de luta antirracista e as potencialidades do contato entre docentes de história e o movimento negro para a implementação da Lei I0.639/03. Dissertação (Mestrado em Educação). Programa de Pós-Graduação em Educação, Universidade Federal do Rio de Janeiro, 2018. MARCHA Zumbi. Por uma política nacional de combate ao racismo e à desigualdade racial: Marcha Zumbi dos Palmares contra o racismo, pela cidadania e a vida. Brasília: Cultura Gráfica e Editora, I996.

MARIELLE Franco. Quem é Marielle?. Disponível em: <https://www.mariellefranco.com.br/quem-e-marielle-franco-vereadora $>$. Acesso em: 2I set. 2018.

MNU - Movimento Negro Unificado. Quem somos. Disponível em: 〈http://mnu.org.br/quem-somos〉. Acesso em: 2 set. 2018.

MOVIMENTO NEGRO UNIFICADO - MNU. I978-I988: Io anos de luta contra o racismo. São Paulo: Confraria do Livro, I988.

NASCIMENTO, Abdias. Teatro experimental do negro: trajetória e reflexões. Estudos Avançados, v. I8, n. 50, jan.-abr. 2004. http://dx.doi.org/I0.I590/SoI03-40I42004000I000I9.

ONUBR - Nações Unidas no Brasil. \#Vidas negras: você sabe o que é filtragem racial?. Publicado em I4/II/20I7. Disponível em: 〈https://nacoesunidas.org/voce-sabe-o-que-e-filtragem-racial〉. Acesso em: 28 ago. 2018.

. Vidas Negras. Pelo fim da violência contra a juventude negra no Brasil. 20I7. Disponível em: $\langle$ https://nacoesunidas.org/campanha/vidas-negras $\rangle$. Acesso em: 28 ago. 2018.

PAINEL BAP. Primeiro painel de consumidores afro-brasileiro. Disponível em: <https://www.painelbap. com.br/painel-consumidores-afrobrasileiro >. Acesso em: 2I set. 2018.

PEREIRA, Amilcar Araujo. "Por uma autêntica democracia racial!": os movimentos negros nas escolas e nos currículos de história. História Hoje, v. I, n. I, jun. 20I2, p. III-I28. https://doi.org/I0.20949/rhhj. viir.2I.

. O mundo negro: relações raciais e a constituição do movimento negro contemporâneo no Brasil. Rio de Janeiro: Pallas, 20I3.

REAJA ou Será Morto. Geledés Instituto da Mulher Negra. Disponível em: <https://www.geledes.org.br/ tag/reaja-ou-sera-morto >. Acesso em: Io set. 2018.

SANTOS, Joel Rufino dos. O Movimento Negro e a crise brasileira. Política e Administração, v. 2, jul.-set. de I985, p. 287-307.

UNEAFRO Brasil. Rede de articulação e formação de jovens e adultos moradores de regiões periféricas do Brasil que se organiza em torno de núcleos. Disponível em: 〈https://uneafrobrasil.org/>. Acesso em: 2I set. 2018.

WAISELFISZ, Julio Jacobo. Mapa da violência 20I6: homicídios por armas de fogo no Brasil. Rio de Janeiro: Flacso Brasil, 20I6. Disponível em: <https://www.mapadaviolencia.org.br/pdf2oI6/Mapa20I6_armas_web.pdf $>$. Acesso em: Iำ set. 2018.

WERNECK, Jurema; MENDONÇA, Maisa; WHITE, Evelyn C. (Org.). O livro da saúde das mulheres negras: nossos passos vêm de longe. Rio de Janeiro: Pallas/Criola, 2000. 